\title{
An analysis of calls referred to the emergency 999 service by NHS Direct
}

P Gaffney, S Crane, G Johnson, M Playforth

\begin{abstract}
Introduction-NHS Direct was launched in West Yorkshire in April 1999. A 999 ambulance can be dispatched to the patient as a result of a call to NHS Direct. The aim of this study is to compare cases that had been referred by NHS Direct via the 999 service, with those who had dialled 999 themselves.

Methods-The study was carried out in three accident and emergency (A\&E) departments in West Yorkshire, between 1 April 1999 and 21 August 1999. NHS Direct generated 999 calls were identified. The comparison group was selected at random from a list of all other 999 cases attending the three departments. The study involved retrieving basic demographic data, as well as duration of symptoms before dialling 999, triage category on arrival in $A \& E$ and disposal of patient. Ethical approval and statistical advice were obtained.
\end{abstract}

Results-91 NHS Direct generated 999 calls were identified. Of the comparison group (260 cases), 28 were excluded from the study. There were no differences in the triage categories assigned to the two groups on arrival in $\mathrm{A} \& \mathrm{E}$. There were notable differences in presenting complaint between the two groups and in particular, trauma was less common among the NHS Direct patients $(6.6 \%)$ compared with those who had self dialled $(37.5 \%)$. Patients who had first called NHS Direct were younger $(p=0.033)$ and had endured their symptoms for longer $(p<0.001)$; they were less likely to be admitted, and if discharged, were less likely to have follow up arranged $(\mathrm{p}=0.014)$.

Conclusions-Both groups received similar triage categories suggesting that severity of illness is equally well assessed by self as by NHS Direct. There are large differences in case mix between the two groups studied and these almost certainly explain the differences in outcome.

(Emerg Med f 2001;18:302-304)

Keywords: NHS Direct; emergency 999 calls; ambulance service

NHS Direct is the new nurse led telephone advice service that has spread quickly across England since the government confirmed its commitment to the idea in its white paper The New NHS: modern, dependable (1997). ${ }^{12}$ This rapid expansion has fuelled criticism that large amounts of money are being consumed before adequate time has been allowed for formal evaluation. ${ }^{3}$ The service in West Yorkshire was launched on 1 April 1999 and is run by the West Yorkshire Metropolitan Ambulance Service (WYMAS). The new service aims to direct callers to the "right care at the right time from the right person". One of the decisions that can be reached after telephone consultation with an NHS Direct nurse is to send a 999 ambulance to the patient. The purpose of this work was to compare patients referred by NHS Direct to accident and emergency (A\&E) departments via 999 ambulance with those who arrived in A\&E having dialled 999 themselves.

\section{Methods}

The study was performed for the first 20 weeks after the launch of NHS Direct in West Yorkshire. Three A\&E departments were included, namely St James's University Hospital (Leeds), Pinderfields General Hospital (Wakefield) and Pontefract General Infirmary. Ethical approval was obtained from the research ethics committees of each hospital, NHS Direct and the WYMAS.

Details of all calls received by NHS Direct (including the outcome in terms of disposal) are automatically logged into a computer database. Those calls subsequently referred to the 999 service, are automatically logged by WYMAS as originating from NHS Direct. WYMAS (which runs NHS Direct in West Yorkshire) was therefore able to release details of all patients referred by NHS Direct to the 999 service over this period and who were brought to each of the three studied departments. The departments themselves released complete lists of other 999 cases presenting during the same study period. A comparison group was selected from this large group of patients who had dialled 999 themselves, using a random number generator. It was decided that the comparison group should be 2.8 times the size of the NHS Direct group as the total number of patients attending all of these three departments was 2.8 times the number of calls received by NHS Direct during the study period. Specifically excluded were patients upgraded to a 999 response by NHS Direct for non-medical reasons (such as no transport), patients brought dead on arrival and patients for whom the general practitioner had called 999 or who were told to ring 999 by their general practitioner. A\&E records were identified for all included patients and were reviewed retrospectively. Data were gathered with respect to age, sex, presenting complaint, duration of symptoms before attendance at 
A\&E, Manchester triage category assigned, and disposal from $A \& E$. Categorical data were analysed using the $\chi^{2}$ test. Continuous variables were compared using $t$ tests (parametric) or Mann-Whitney U test (non-parametric).

\section{Results}

During the study period 91 patients were referred by NHS Direct to the 999 service for medical reasons. In total there were 17883 cases brought to the three A\&E departments by 999 ambulance over the same period. From an initial comparison group of 260 patients, 28 were excluded (two were dead on arrival, 26 had seen their GP before dialling 999) leaving 232 patients for comparison. Data relating to age, sex, duration of symptoms before presentation and triage category assigned are summarised in table 1. Differences in age and duration of symptoms between the two groups reached statistical significance. NHS Direct patients were younger and had suffered their symptoms for a longer period. Figure 1 presents data in relation to presenting complaint. Trauma was almost exclusively represented by the self dialled group. The vast majority of patients arriving in A\&E having first dialled NHS Direct, complained of non-traumatic medical and surgical conditions. Figure 2 summarises disposal data and shows an overall significant difference in outcome between the two groups. This is mainly explained by the fact that a much larger proportion of patients in the self

Table 1 Baseline characteristics of NHS Direct and self dialled groups

\begin{tabular}{lccrrr}
\hline Characteristic & $\begin{array}{c}\text { NHS Direct } \\
(n=91)\end{array}$ & \multicolumn{2}{c}{$\begin{array}{c}\text { Self dialled } \\
(n=232)\end{array}$} & $p$ Value \\
\hline Male sex (\%) & $50(55)$ & \multicolumn{2}{c}{120} & $(52)$ & 0.622 \\
Mean age (y) (SD) & $46.0(22.4)$ & $52.2(25.7)$ & 0.033 \\
Median duration of symptoms (h) (IQR) & 6 & $(1-48)$ & 1 & $(1-12)$ & $<0.001$ \\
Triage category (\%) & 3 & $(3)$ & 8 & $(3)$ & \\
1 & 13 & $(14)$ & 35 & $(15)$ & \\
2 & 48 & $(53)$ & 125 & $(54)$ & 0.985 \\
3 & 27 & $(30)$ & 64 & $(28)$ & \\
4 & 0 & $(0)$ & 0 & $(0)$ & \\
5 & & & & & \\
\hline
\end{tabular}

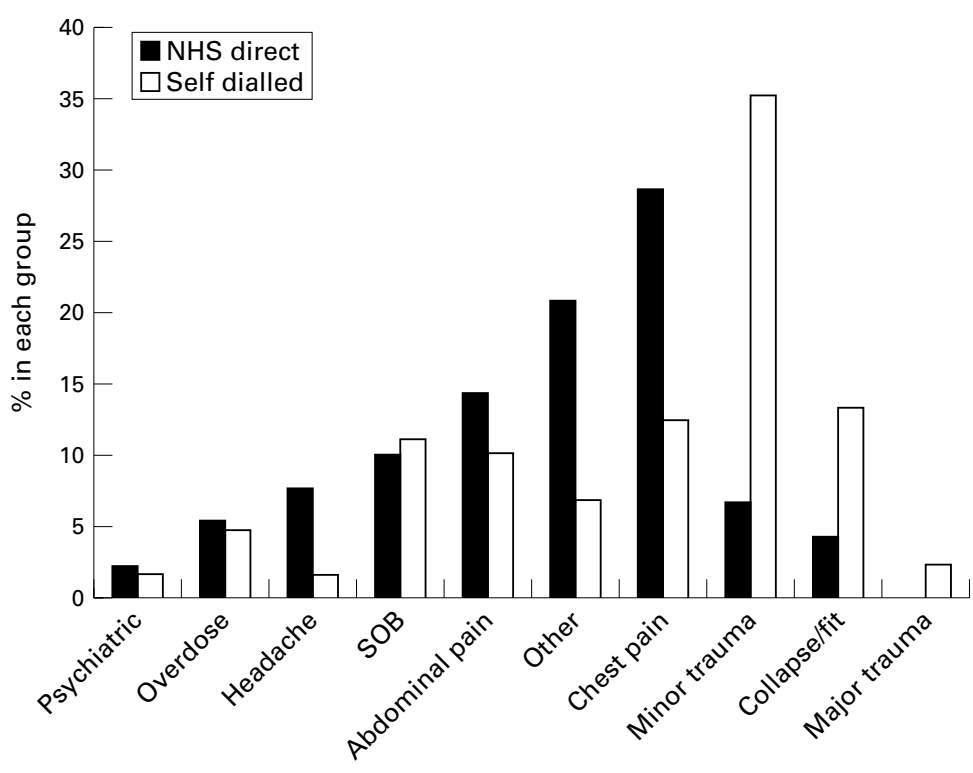

Figure 1 Presenting complaint (\%) in each group.

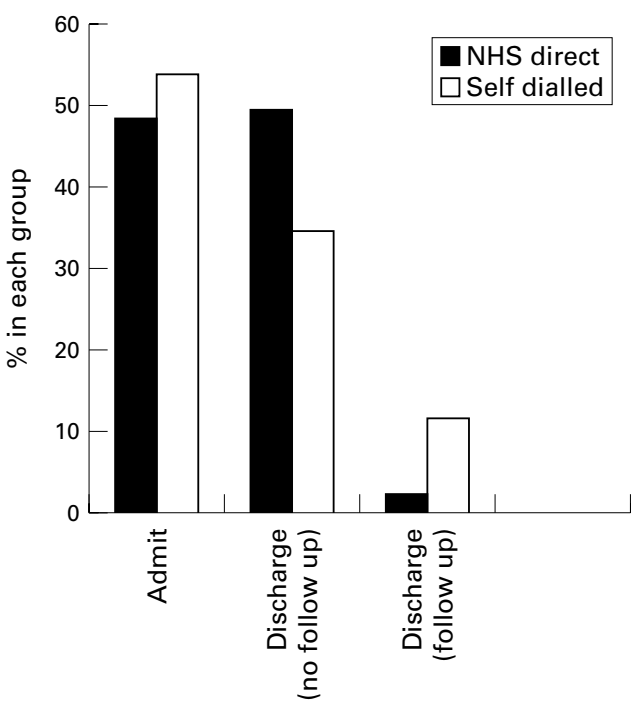

Figure 2 Disposal (\%) of each group. $(p=0.014$ for overall difference in proportions between the two groups).

dialled group was discharged with follow up arranged.

\section{Discussion}

Scant published work has emerged on NHS Direct, but this is unsurprising as the service is still in its infancy. It has been reported that most callers find the advice useful, largely because of the element of reassurance offered. ${ }^{4}$ Anecdotal evidence has been published in relation to the impact of the new service on advice calls to A\&E departments and the reduction thereof. ${ }^{5}$ This is the first study we are aware of that looks at 999 calls referred by NHS Direct.

The patients in the NHS Direct group tended to be younger and have suffered their symptoms for longer. This may reflect the greater accessibility of the new service for young workers in comparison to more conventional forms of medical care. Indeed it may be that the NHS Direct group represents an entirely new group of patients arriving in $A \& E$ departments via 999 ambulance, who previously may not have done so.

The data on triage categorisation suggest no differences between the groups in terms of assessment of severity of presenting illness by NHS Direct or self reported.

This study was performed during the first 20 weeks after the establishment of NHS Direct in West Yorkshire. One could reasonably expect a low threshold for referral to the 999 service at this early stage (because of the relative inexperience of the NHS Direct nurses in telephone triage). This may, in part, explain the subsequent lower rate of hospital admission in these patients compared with those who self dialled 999. It would be interesting to repeat a similar study when the service is more firmly established. However, it is much more likely that the differences in disposal reflect baseline differences in case mix. Patients with trauma and elderly patients without trauma seem more likely to dial 999 themselves, a service they are more familiar with. The fact that admission is more likely in the self dialled group and that 
outpatient follow up is more likely to be arranged, almost certainly reflects the differences in case mix that were observed. In particular trauma patients are much more likely to have follow up arranged (for example, $\mathrm{A} \& \mathrm{E}$ clinic or fracture clinic), and these patients were almost exclusively seen in the self dialled group.

Finally, those referred by NHS Direct represent only a tiny proportion $(0.5 \%)$ of the overall number of 999 cases at the three departments (amounting to approximately one to two patients per department per week). If NHS Direct is to succeed in reducing the number of patients attending A\&E departments via 999, a much larger number of patients will have to use the service rather than dial 999 themselves.
We would like to thank Wendy Parsons for statistical advice and WYMAS for releasing patient details.

Contributors

Paul Gaffney and Steven Crane initiated the research, designed the study, collected and analysed data, and wrote and revised the manuscript. Graham Johnson discussed core ideas and edited the manuscript. Mike Playforth discussed study design and helped with data collection. Both Paul Gaffney and Steven Crane act as guarantors.

Funding: none.

Conflicts of interest: none.

1 Department of Health. The New NHS: modern, dependable. Cmd 3807. London: Stationery Office, 1997.

2 NHS Executive. NHS Direct-final stage of national rollout. NHS Executive. NHS Direct-final stage of national
Health Service Circular 1999/02, 9 February 1999.

3 Florin D, Rosen R. Evaluating NHS Direct. BMF 1999;319: $5-6$.

4 O'Cathain A, Munro JF, Nicholl JP, et al. How helpful is NHS Direct? Postal survey of callers. BMF 2000;320:1035.

5 Gaffney P, Johnson G. Evidence in favour of NHS Direct. [Letter]. Arch Dis Child 2000;82:336. 